\title{
CONSTITUTIVE MODELS OF PAVEMENT ASPHALTIC LAYERS BASED ON MIXTURE COMPOSITIONS
}

\author{
Artur ZBICIAK, Karol BRZEZIŃSKI, Rafał MICHALCZYK \\ Faculty of Civil Engineering, Warsaw University of Technology, 16 Armii Ludowej Ave., 00-637 Warsaw, Poland
}

Received 28 Jun 2015; accepted 28 Sep 2015

\begin{abstract}
The design of flexible and semi-rigid pavements by applying mechanistic-empirical methods involves the determination of the stress and strain states in accordance with the assumptions of continuum mechanics. Advanced computational models should take into account the rheological properties of asphalt layers. Precise identification of visco-elastic parameters of asphalt aggregate mixtures requires a lot of expensive laboratory experiments. The objective of this paper is to propose a new method allowing the identification of visco-elastic constitutive parameters based only on the mixture composition. The effectiveness of the proposed approach is exemplified in the paper by numerical calculations. Two linear rheological models were analyzed: the classical Burgers model and the Huet-Sayegh model described by fractional derivatives. Constitutive parameters of both models were obtained from the appropriate optimization algorithms and numerical techniques for determining inverse Laplace transforms.
\end{abstract}

Keywords: asphalt pavements, asphalt-aggregate mixtures, mechanistic-empirical design, constitutive models, rheology, visco-elasticity, Laplace transforms, curve fitting.

\section{Introduction}

Degradation of road pavement structures is a very complex process. Because of the difficulty of modeling this phenomenon, empirical design methods are usually used. Empirical methods require long-term observations of roads built and operated under certain conditions (the material used, the subsoil, traffic load, weather conditions, etc.). The main difficulty in the application of empirical methods is taking into account any differences with respect to the typical conditions in which they were developed.

Therefore, a more universal group of methods in use are so-called mechanistic-empirical methods (Judycki 2014). The use of mechanistic-empirical methods requires a solid mechanics problem solution in order to determine the stress, strain and displacement states within critical points of the analyzed structure. The solution strongly depends on the loading and the material properties.

The most widely used model of pavement structure is an axisymmetric multi-layered elastic half-space. It is assumed that each layer has a predetermined thickness, is homogeneous and isotropic and characterized by Young's modulus and Poisson's ratio. The load is modeled as uniformly distributed pressure acting on the circular surface. Such a load roughly corresponds to the pressure of the car wheel. The assumption of elasticity is a significant simplification, as asphaltic mixtures are visco-elastic materi- als. The use of a visco-elastic model provides for better estimation of the strain and the stress states. This allows the cost of its maintenance to be estimated with greater accuracy and the cost of its construction minimized by using the cost benefit analysis at the early design stage (Zavadskas et al. 2008).

There are many rheological models describing precisely the visco-elastic behavior of asphalt aggregate mixtures. On the other hand, these models are rarely used in practical pavement design, because of the greater complexity of the computation and the difficulties associated with the adoption of the appropriate parameters of these models. The identification process of rheological models requires expensive laboratory tests of asphaltic mixtures (Radziszewski et al. 2014).

Thus, in practical pavement design the simplest way of taking into account rheological effects is to replace the elastic modulus with stiffness modulus. Such an approach requires knowledge of the load time and operating temperature for asphaltic material. Using the stiffness modulus in the calculation process allows laboratory tests to be dropped in the early design stages. If the composition of the mixture and the basic properties of the binder are known, the stiffness of asphaltic mixtures can be estimated by using empirical formulas or nomograms. Thus, this approach allows us to determine the elastic modulus

Corresponding author: Karol Brzeziński

E-mail:k.brzezinski@il.pw.edu.pl 
defined in specified temperature and loading time. Such a simplified procedure results in an elastic material model with an elastic modulus depending on time and temperature.

The novel approach of our paper consists of the extension of the above-mentioned method. Thus, it is possible to identify the parameters of any visco-elastic rheological model of asphaltic mixtures based on their composition. The proposed solution constitutes an approximate way to obtain a full characterization of the visco-elastic properties of asphaltic mixtures. It is a tool which greatly expands the possibilities of analysis of pavement structures at an early stage of the design, without incurring the costs of determining visco-elastic properties by means of laboratory tests.

In order to verify the proposed method sample calculations were performed. On the basis of the known mixture composition the stiffness moduli were obtained by applying the appropriate empirical formulas. Then the obtained results were compared with the results based on a laboratory test (four-point bending test). The next stage of the method consists of an identification procedure for certain rheological models. In the paper the parameters of two visco-elastic schemes have been identified. We analyzed the classical Burgers model and the Huet-Sayegh model described by fractional derivatives.

\section{Determining stiffness moduli}

The above-mentioned method requires the knowledge of asphaltic mixtures' stiffness moduli. They can be determined, in an approximate way, from the mixture composition by using empirical formulas. The procedure for obtaining the stiffness modulus consists of two steps. Initially, the stiffness modulus of the binder needs to be determined at a given temperature and load time. This can be done only by knowing the results of basic laboratory tests: the softening point test and the penetration value (typically at $25^{\circ} \mathrm{C}$ ) (Gawel et al. 2014). Afterwards, the binder stiffness can be determined by using Van der Poel's nomogram. The nomogram results can be simulated by applying special computer programs such as PONOS (De Bats 1973).

The second step is to determine the stiffness modulus of the asphalt aggregate mixture. The asphaltic mixture is a composite material. Thus, both the characteristics of the individual components and the proportions between them have a significant effect on its properties. There are different groups of methods of determining the stiffness modulus of the asphalt mixtures. One of them is discrete element modeling joining the concept of finite element method (FEM) and discrete element method (DEM) (Rimša et al. 2014). In our paper we use empirical formulas, wherein the stiffness modulus is determined based on stiffness of the binder and the ratio between mixture components. In this paper, Bonnaure's formula was used (Bonnaure et al. 1977), which is consistent with the BANDS Shell program (Brzeziński, Zbiciak 2014).
In the above-mentioned method, the stiffness modulus of the asphalt aggregate mixture is defined in two ranges of binder stiffness. For the purposes of this paper a formula in the range from $5 \mathrm{MPa}$ to $1 \mathrm{GPa}$ was used:

$$
\begin{aligned}
& \log \left|E^{*}\right|=\frac{M+N}{2}\left(\log S_{b}-8\right)+\ldots \\
& +\frac{M-N}{2}\left|\log S_{b}-8\right|+B,
\end{aligned}
$$

where:

$$
\begin{gathered}
B=8.0+5.68 \cdot 10^{-3} V_{g}+2.135 \cdot 10^{-4} V_{g}^{2} ; \\
M=\frac{1.12(A-B)}{\log 30} ; \\
N=0.6 \log \left(\frac{1.37 V_{b}^{2}-1}{1.33 V_{b}-1}\right)
\end{gathered}
$$

where: $|E *|$ denotes the asphaltic mixture's stiffness modulus (sometimes also called the dynamic modulus), $S_{b}$ is the stiffness modulus of the binder, and $V_{g}, V_{b}$ and $V_{a}$ are percentage volumetric content of the aggregates, asphalt and voids in the mixture.

It follows that in order to estimate the stiffness modulus knowledge of the binder's and asphaltic mixture's basic parameters is sufficient. These values can be easily obtained from simple laboratory tests or adopted on the basis of the technological requirements (Sybilski 2008, 2010). The stiffness modulus determined by using Van der Poel's nomogram corresponds to the values of the secant modulus set in the creep test (creep modulus). The authors of this paper note that the values of the stiffness modulus defined for the same mixture composition at a given temperature and different times can be treated as the load creep test results. On this basis, an "artificial curve creep" can be formed in a simple way. Subsequently it may be used to identify the parameters of any linear visco-elastic rheological model. There is a good correspondence between the secant modulus values and the dynamic modulus when a particular relationship between frequency and time of the load is applied. Thus, the scope of applicability of the method can be expanded for cyclic tests. Such a relationship made it possible to compare the results obtained with an empirical method with the results of experimental investigations. In order to verify the method sample calculations were performed. On the basis of the known composition of the mixtures, parameters of two rheological models, Burgers and HuetSayegh (see Fig. 1), were identified.

Then the models with obtained parameters were tested and the test results were discussed. 

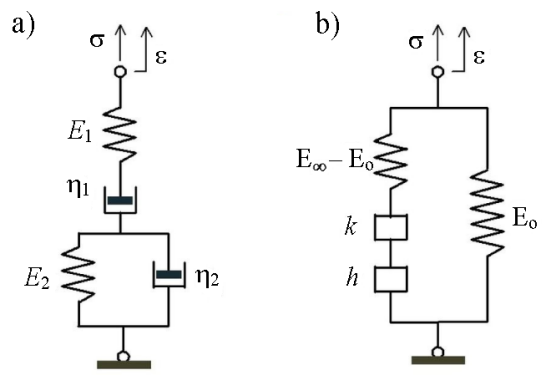

Fig. 1. Visco-elastic rheological Burgers (a) and Huet-Sayegh (b) structures

\section{Identification of rheological models based on mixture composition}

\subsection{Experimental data}

Sample calculations of rheological models' parameter identification procedure were made on the basis of the composition of two typical mixtures: asphalt concrete with a maximum grain size of $22 \mathrm{~mm}$ for the base course (AC22P) and asphalt concrete with a maximum grain size of $16 \mathrm{~mm}$ for the binder course (AC16W) (see Sybilski 2008). Both mixtures were made with the same 50/70 asphalt binder (penetration at $25^{\circ} \mathrm{C}$ equals $67[0.1 \mathrm{~mm}$ ], the softening point of $48^{\circ} \mathrm{C}$ ). The parameters of asphaltic mixture composition, important for estimating the stiffness modulus, are compiled in Table 1.

Table 1. Volumetric content of mixture components

\begin{tabular}{l|c|c|c}
\hline $\begin{array}{c}\text { Type of asphaltic } \\
\text { mixture }\end{array}$ & $\begin{array}{c}V_{b}, \\
(\mathrm{v} / \mathrm{v})\end{array}$ & $\begin{array}{c}V_{g}, \\
(\mathrm{v} / \mathrm{v})\end{array}$ & $\begin{array}{c}V_{v}, \\
(\mathrm{v} / \mathrm{v})\end{array}$ \\
\hline AC22P & $8.8 \%$ & $86.1 \%$ & $5.1 \%$ \\
$\mathrm{AC} 16 \mathrm{~W}$ & $10.2 \%$ & $85.1 \%$ & $4.7 \%$ \\
\hline
\end{tabular}

The asphalt binder's stiffness moduli were estimated with the Van der Poels nomogram. Then the stiffness moduli of mixtures were obtained by applying Eqn (1). The results were compared with those obtained on the basis of the four-point bending test at $10{ }^{\circ} \mathrm{C}$ and are shown in Figure 2.

The average relative error estimation amounted to approximately $17 \%$ for the AC22P mixture and approximately $14 \%$ for the AC16W mixture. The determined

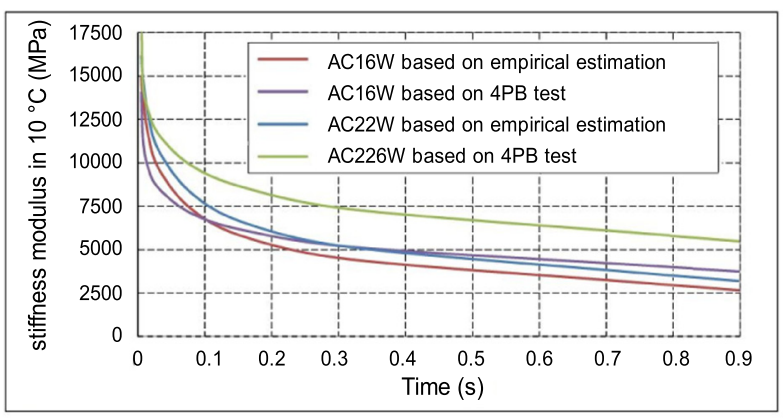

Fig. 2. Comparison of the results of estimated stiffness moduli and those obtained in laboratory tests results were considered as acceptable and used in the main part of the calculation.

The next step, which is a novel approach, uses the estimation results of the stiffness moduli obtained from the mixture composition to identify the parameters of rheological models.

\subsection{Burgers rheological model}

Van der Poel's modulus $E_{p}(\Delta t)$ can be interpreted as the secant modulus determined in a creep test at constant stress $\sigma_{0}$, where $\varepsilon(\Delta t)$ is the resulting strain after time $\Delta t:$

$$
E_{p}(\Delta t)=\frac{\sigma_{0}}{\varepsilon(\Delta t)} .
$$

As assumed before, there is a good correspondence between the secant modulus values and the stiffness modulus determined in the cyclic test. Thus, it is reasonable to compare the results of the cyclic tests and the results obtained with an empirical method, as shown in Figure 2. Moreover, it is possible to use an exact analytical solution of the Burgers model creep test in order to determine Van der Poel's modulus (Nowacki 1963; Christensen 1982):

$$
\frac{1}{E_{p}(\Delta t)}=\frac{1}{E_{1}}+\frac{1}{\eta_{1}} \Delta t+\frac{1}{E_{2}}\left[1-\exp \left(-\frac{E_{2}}{\eta_{2}} \Delta t\right)\right],
$$

where: $E_{1}, E_{2}, \eta_{1}, \eta_{2}$ represent material parameters. Eqn (6) and the results of the evaluation of the stiffness modulus estimated with the empirical method (Eqn (1)) were used to determine the rheological parameters of the Burgers model for asphalt mixtures on the basis of mixture composition (see Table 2).

Table 2. Rheological parameters of the Burgers model

\begin{tabular}{l|c|c|c|c}
\hline $\begin{array}{c}\text { Type of asphaltic } \\
\text { mixture }\end{array}$ & $\begin{array}{c}E_{1}, \\
(\mathrm{MPa})\end{array}$ & $\begin{array}{c}E_{2}, \\
(\mathrm{MPa})\end{array}$ & $\begin{array}{c}\eta_{1}, \\
(\mathrm{MPa})\end{array}$ & $\begin{array}{c}\eta_{2}, \\
(\mathrm{MPa})\end{array}$ \\
\hline AC22P & 17783 & 14668 & 4888 & 803 \\
AC16W & 16623 & 12804 & 3928 & 690 \\
\hline
\end{tabular}

Figure 3 shows the results of the theoretical creep test carried out by applying the Burgers model compared with the results estimated with Eqn (1).

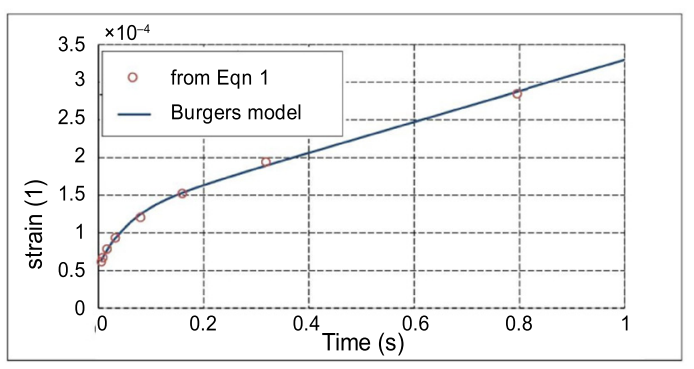

Fig. 3. Comparison of the results of theoretical creep test for AC22P mixture, estimated based on Eqn (1) and calculated with Burgers model 
The adopted material model represents the properties of mixtures estimated with Eqn (1) reasonably well.

\subsection{Huet-Sayegh rheological model}

The Burgers rheological structure, considered in Section 2.2, is composed of classical, elastic and viscous elements. As shown in many studies, the possibilities of representing the behavior of asphaltic mixtures with Burgers model within a wide range of temperature and frequency are limited (Kim 2009; Wang 2011; Zbiciak 2013). A more adequate model of visco-elastic behavior is the Huet-Sayegh (HS) structure (see Fig. 1b). This model contains non-classical linear visco-elastic elements whose constitutive properties are described by fractional derivatives (Podlubny 1999; Butera, Di Paola 2014; Di Mino et al. 2016; Grzesikiewicz et al. 2013; Zbiciak 2012). The fractional order systems theory has been used in many branches of technics, including electrical engineering, mechanical engineering and construction.

Identification of asphalt mixture models based on the mixture composition by using the HS structure is difficult. The fundamental problem is that we cannot formulate any analytical formula for the HS creep function, although it was very easy in the case of the Burgers model (see Eqn (6)). In the case of the HS model, obtaining such a formula is difficult, because of the need to solve a differential equation of fractional order. There is a possibility of integrating such equations by using the algorithm proposed by Grzesikiewicz et al. (2013) which also takes into account the nonlinear phenomenon (nonlinear viscosity or plasticity). In the case of the Huet-Sayegh rheological structure identification, the optimization algorithm requires the fractional differential equations to be solved many times. Such a process is very time-consuming.

In our paper, the issue of the HS structure identification has been solved by using the concept described by Zbiciak and Grzesikiewicz (2011), wherein the characteristics of the fractional model (including creep) were obtained by applying numerical algorithms for determining the inverse Laplace transforms (see Valsa, Brancik 1998). Use of these algorithms, along with the appropriate optimization procedures implemented in Matlab, allows for effective solution of the identification problem.

Numerical determination of the creep characteristics of the HS model requires the understanding of its transfer function $E^{*}(s)$, which results directly from the formula for the complex modulus $E^{*}(i \omega)$, when substituting $i \omega=s$. The complex modulus of the HS structure has the following form:

$$
E^{*}(i \omega)=E_{\mathrm{o}}+\frac{E_{\infty}-E_{\mathrm{o}}}{1+\delta(i \omega \tau)^{-k}+(i \omega \tau)^{-h}},
$$

where: $E_{\mathrm{o}}$ - static modulus (for $\omega \rightarrow 0$ ); $E_{\infty}$ - the glass transition modulus (for $\omega \rightarrow \infty$ ); $h, k$ - parameters obeying the condition $0<k<h<1 ; \delta$ - dimensionless constant; $\tau$ - characteristic time.
In the case of the linear systems analyzed in this paper, the following relationship combining the stresses and strains is valid:

$$
\sigma^{*}(s)=E^{*}(s) \varepsilon^{*}(s),
$$

where $\sigma^{*}(s)$ and $\varepsilon^{*}(s)$ are the Laplace transforms of the stress $\sigma(t)$ and the strain $\varepsilon(t)$ states.

From the analytical form of the Laplace transform for the force signal modeling the creep test, it is possible to obtain the response of the Huet-Sayegh model. As indicated previously, this operation must be carried out numerically with the algorithms described by Valsa and Brancik (1998) (see also Liu 2001).

The results for identification of the HS rheological model for two selected asphalt mixtures are summarized in Table 3.

The graph in Figure 4 shows the creep test theoretical curve performed with the rheological HS model for AC16W mixture. Moreover, Figure 4 shows the results obtained with the analytical model described by Eqn (1). One can see that the proposed method yielded good agreement of the results for the theoretical creep test.

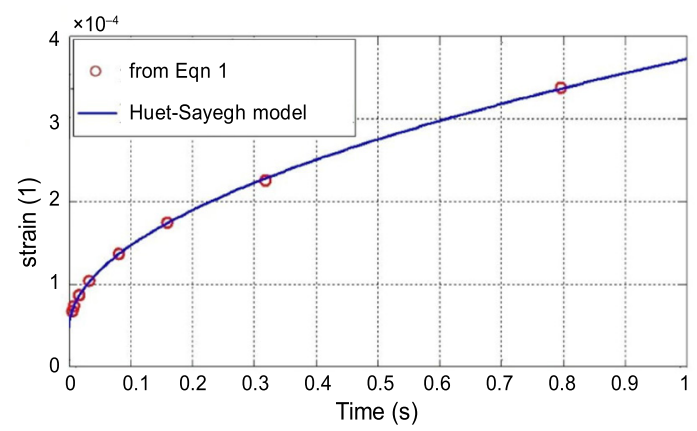

Fig. 4. Comparison of results for theoretical creep test for AC16W mixture, estimated by Eqn 1 and calculated with the Huet-Sayegh model

With the constitutive parameters of rheological models for certain asphalt aggregate mixtures it is possible to construct another interesting characteristic related to the dynamic properties of the analyzed models. The diagrams shown in Figure 5 visualize Cole-Cole and Black graphs for a Huet-Sayegh model of AC22P mixture. The ColeCole graph relates storage modulus (real part of complex modulus describing elastic properties of the model) to loss modulus (imaginary part of complex modulus describing viscous properties of the model). The Black diagram relates phase angle to dynamic modulus (absolute value of complex modulus).

Another characteristic of the Huet-Sayegh model for AC22P mixtures is depicted in Figure 6. The dynamic modulus master curve describing dynamic modulus as a function of frequency is shown in Figure 6a and the phase angle vs. frequency is visualized in Figure 6b. It should be emphasized that all the Huet-Sayegh characteristics visualized in Figures 5 and 6 are similar to those 

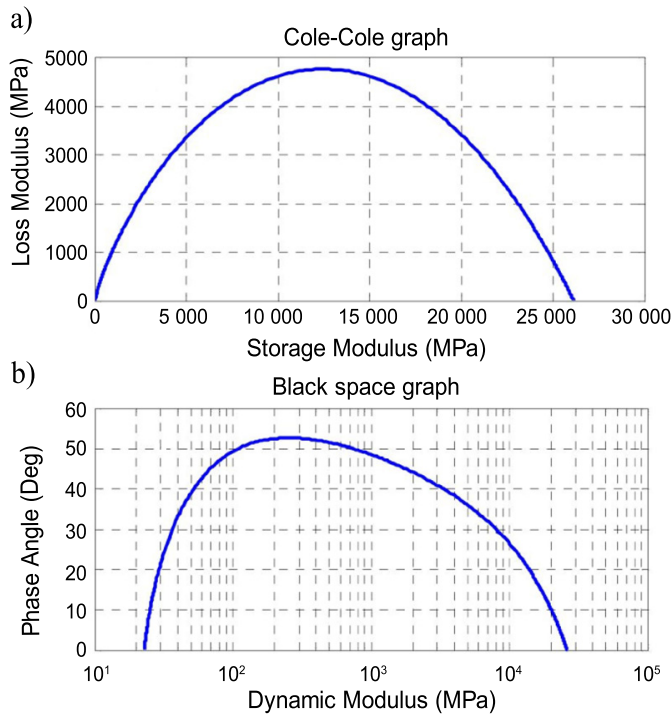

Fig. 5. Cole-Cole graph (a) Black diagram (b) for AC22P applying the Huet-Sayegh model
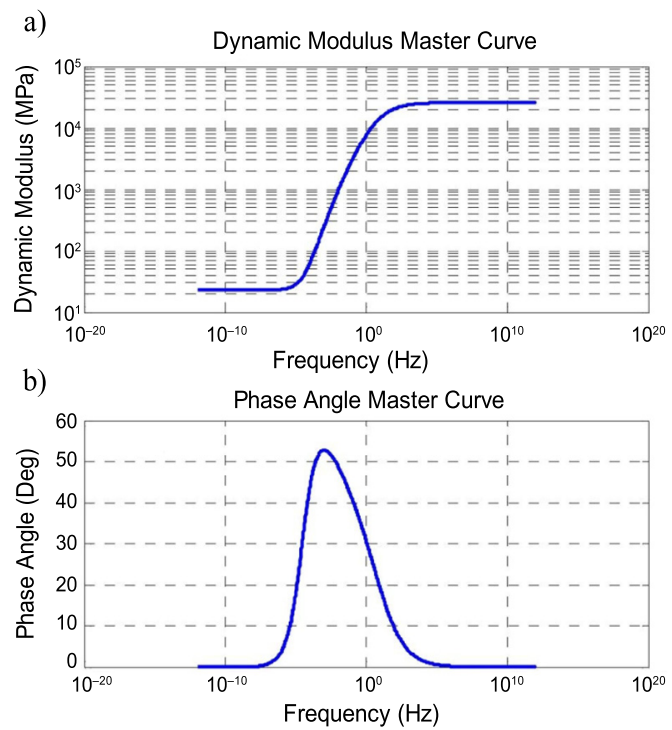

Fig. 6. Dynamic modulus (a) and phase angle (b) master curves for AC22P with the Huet-Sayegh model

presented in the literature (see e.g. Kim 2009; Zbiciak, Michalczyk 2014).

The algorithms for calculation of inverse Laplace transforms applied in this paper in the process of identification of a rheological model can be used in order to find the response of the model subjected to harmonic or step excitations. The diagrams shown in Figure 7 represent relaxation curves of the Huet-Sayegh and Burgers models for AC22P mixtures. These curves visualize the response of the mixture to step strain excitation of $10^{-6}(1 \mu$ strain). Good convergence of both curves in Figure 7 is evident.

On the other hand, the initial stresses shown in Figure 7 for $t=0$ are different in the two models. The value of the Burgers initial stress corresponds to rheological

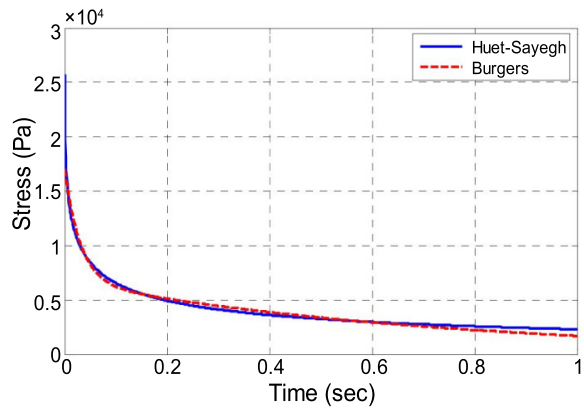

Fig. 7. Relaxation curves for AC $22 \mathrm{P}$ with Burgers and HuetSayegh models (step strain excitation of $10^{-6}$ )

parameter $E_{1}$, taking into account the amplitude of excitation equal to $10^{-6}$ (compare Fig. 7 and Table 2) and the Huet-Sayegh initial stress from Figure 7 corresponds to the glass transition modulus $E_{\infty}$ (see Table 3).

Table 3. Calculated parameters of the Huet-Sayegh model

\begin{tabular}{l|c|c|c|c|c|c}
\hline $\begin{array}{c}\text { Type of asphaltic } \\
\text { mixture }\end{array}$ & $\begin{array}{c}E_{\mathrm{o}} \\
(\mathrm{MPa})\end{array}$ & $\begin{array}{c}E_{\infty} \\
(\mathrm{MPa})\end{array}$ & $k$ & $h$ & $\tau$ & $\delta$ \\
\hline AC22P & 23 & 26129 & 0.421 & 0.764 & 0.576 & 3.911 \\
AC16W & 10 & 21527 & 0.501 & 0.577 & 0.994 & 5.219 \\
\hline
\end{tabular}

\section{Conclusions}

The results of computer calculations presented in this article indicate the correctness of the proposed algorithm. The algorithm was used in order to identify visco-elastic constitutive models of asphalt aggregate mixes based on the mixture composition. It should be highlighted that the proposed method is also applicable in the case of nonclassical models of fractional order for which the formulation of analytical creep formulas would be problematic. Rheological models whose parameters are identified by the proposed method can be used in the process of semi-rigid and flexible pavement construction design. The design process needs the strain and the stress states at critical points of pavement to be calculated. These calculations should be carried out with visco-elastic models of asphalt layers.

On the other hand, the presented method is based on the creep characteristics at a certain temperature. Thus, it cannot correctly reflect the behavior of the asphalt mixture within a wide temperature-frequency range (Zbiciak, Michalczyk 2014). Full identification of the rheological model of asphalt mixture requires a series of cyclic bending tests at different frequencies and temperatures. Moreover, the parameters identified with the method presented in the paper should also be proved with appropriate laboratory tests. Nevertheless, by applying our method one can avoid labor-intensive and cost-consuming laboratory tests at the early design stages, as pointed out in the introduction to this paper.

Further explorations of problems related to the issue of temperature-frequency dependence of rheological 
models by applying the method proposed herein will be published in a subsequent paper.

\section{References}

Bonnaure, F.; Gest, G.; Gravios, A.; Ugé, P. 1977. A new method of predicting the stiffness of asphalt paving mixtures, AAPT Proceedings 46: 64-104.

Brzeziński, K.; Zbiciak, A. 2014. Analytical methods for estimating stiffness modulus of asphalt mixtures, Engineering and Construction 12: 692-695 (in Polish).

Butera, S.; Di Paola, M. 2014. Fractional differential equations solved by using Mellin transform, Communications in Nonlinear Science and Numerical Simulation 19(7): 2220-2227. https://doi.org/10.1016/j.cnsns.2013.11.022

Christensen, R. M. 1982. Theory of viscoelasticity. New York, NY: Academic Press.

De Bats, F. T. 1973. A computer simulation of Van der Poel's nomograph, Journal of Applied Chemistry and Biotechnology 23: 139-140. https://doi.org/10.1002/jctb.5020230209

Di Mino, G.; Airey, G.; Di Paola, M.; Pinnola, F. P.; D’Angello, G.; Lo Presti, D. 2016. Linear and nonlinear fractional hereditary constitutive laws of asphalt mixtures, Journal of Civil Engineering and Management (in press). https://doi.org/10.3846/13923730.2014.914104

Gaweł, I.; Kalabińska, M.; Piłat, J. 2014. Road asphalts. $2^{\text {nd }}$ ed. revised. Warsaw: Transport and Communication Publishers (in Polish).

Grzesikiewicz, W.; Wakulicz, A.; Zbiciak, A. 2013. Non-linear problems of fractional calculus in modeling of mechanical systems, International Journal of Mechanical Sciences 70: 90-98. https://doi.org/10.1016/j.ijmecsci.2013.02.007

Judycki, J. 2014. Analysis and design of semi-rigid and flexible pavement structures. Warsaw: Transport and Communication Publishers (in Polish).

Kim, Y. R. 2009. Modeling of asphalt concrete. New York, NY: ASCE Press, McGraw-Hill.

Liu, Y. 2001. A direct method for obtaining discrete relaxation spectra from creep data, Rheological Acta 40: 256-260. https://doi.org/10.1007/s003970000132

Nowacki, W. 1963. Theory of creep. Warsaw: Arkady (in Polish).

Podlubny, I. 1999. Fractional differential equations. San Diego: Mathematics in Science and Engineering, Vol. 198, Academic Press.
Radziszewski, P.; Kowalski, K. J.; Król, J. B.; Sarnowski, M.; Piłat, J. 2014. Quality assessment of bituminous binder based on the viscoelastic properties: Polish experience, Journal of Civil Engineering and Management 20(1): 111-120. https://doi.org/10.3846/13923730.2013.843586

Rimša, V.; Kačianauskas, R.; Sivilevičius, H. 2014. Numerical analysis of asphalt mixture and comparison with physical Marshall test, Journal of Civil Engineering and Management 20(4): 570-580. https://doi.org/10.3846/13923730.2014.920413

Sybilski, D. (Ed.) 2008. Asphalt pavements on public roads: WT-2 Asphalt pavements 2008. Warsaw: Road and Bridge Research Institute (in Polish).

Sybilski, D. (Ed.) 2010. Verification of the relationship between the properties of the stiffness modulus results obtained with various laboratory methods according to PN-EN 12697-26. Road and Bridge Research Institute, Warsaw (in Polish).

Valsa, J.; Brancik, L. 1998. Approximate formulae for numerical inversion of Laplace transforms, International Journal of Numerical Modelling 11(3): 153-166. https://doi.org/10.1002/(SICI)10991204(199805/06)11:3<153::AID-JNM299>3.0.CO;2-C

Wang, L. 2011. Mechanics of asphalt, microstructure and micromechanics. New York, NY: McGraw Hill.

Zavadskas, E. K.; Liias, L.; Turskis Z. 2008. Multi-attribute decision-making methods for assessment of quality in bridges and road construction: state-of-the-art surveys, Baltic Journal of Road and Bridge Engineering 3(3): 152-160. https://doi.org/10.3846/1822-427X.2008.3.152-160

Zbiciak, A. 2012. Identification of viscoelastic properties of asphalt-aggregate mixes using classical and fractional rheological models, in Polish-Ukrainian-Lithuanian Transactions: Theoretical Foundations of Civil Engineering. Warsaw: Warsaw University of Technology Publishing House.

Zbiciak, A. 2013. Mathematical description of rheological properties of asphalt-aggregate mixes, Bulletin of the Polish Academy of Sciences: Technical Sciences 61: 65-72. https://doi.org/10.2478/bpasts-2013-0005

Zbiciak, A.; Grzesikiewicz, W. 2011. Characteristics of fractional rheological models of asphalt-aggregate mixtures, Logistyka 6: 4119-4124.

Zbiciak, A.; Michalczyk, R. 2014. Characterization of the complex moduli for asphalt-aggregate mixtures at various temperatures, Procedia Engineering 91: 118-123. https://doi.org/10.1016/j.proeng.2014.12.032

Artur ZBICIAK. PhD, DSc, is an Associate Professor at the Faculty of Civil Engineering of the Warsaw University of Technology. He is a Head of the Division of Theoretical Mechanics and Pavement Modelling. His current research interests are focused on pavement mechanics, non-smooth mechanics, plasticity theory, smart materials and fractional calculus.

Karol BRZEZIŃSKI. MSc, a PhD student at the Department of Theoretical Mechanics and Pavement Modelling of the Warsaw University of Technology. His research interests include mechanistic-empirical design of road pavement construction and fatigue strength analysis.

Rafal MICHALCZYK. MSc, is a Teaching Assistant and a PhD candidate at the Department of Theoretical Mechanics and Pavement Modelling of the Warsaw University of Technology. His research interests primarily concern mechanistic based pavement design. He also has an interest in constitutive modelling of viscoelastic/plastic materials. 